\title{
Circulating Th17 and Tc17 Cells and Their Imbalance with Regulatory T Cells Is Associated with Myocardial Infarction in Young Indian Patients
}

\author{
Thiruvelselvan Ponnusamy ${ }^{1}$, Komarlu Venkatachala Srikanth ${ }^{2}$, Ramanjappa Manjunatha ${ }^{3}$ \\ Vijay V. Kakkar4,5, Lakshmi Mundkur ${ }^{4 *}$ \\ ${ }^{1}$ Research Scholar, Manipal University at Thrombosis Research Institute, Bangalore, India \\ ${ }^{2}$ Narayana Institute of Cardiac Sciences, Bangalore, India \\ ${ }^{3}$ Clinical Research Unit, Thrombosis Research Institute, Bangalore, India \\ ${ }^{4}$ Mary and Gary Western and Tata Molecular Immunology Unit, Thrombosis Research Institute, Bangalore, India \\ ${ }^{5}$ Molecular Immunology Unit, Thrombosis Research Institute, London, United Kingdom \\ Email: *lakshmi.mundkur@triindia.org.in
}

Received 16 October 2015; accepted 27 December 2015; published 30 December 2015

Copyright (C) 2015 by authors and Scientific Research Publishing Inc.

This work is licensed under the Creative Commons Attribution International License (CC BY).

http://creativecommons.org/licenses/by/4.0/

(c) (i) Open Access

\section{Abstract}

Background: Activated inflammatory cells are found in coronary plaques as well as peripheral circulation in patients with acute coronary syndrome. We explored the circulating $T$ cell profile, their reactivity to self-antigens and plasma cytokine levels in Indian patients with Myocardial Infarction. Methods and Results: Intracellular expression of interferon- $\gamma$ Interleukin (IL)-4, IL-17, IL-10 and Foxp3 were determined in $\mathrm{CD}^{+}$and $\mathrm{CD8}^{+} \mathrm{T}$ cells using flow cytometry in patients with ST elevated myocardial infarction (STEMI) $(\mathrm{N}=79)$ and controls $(\mathrm{N}=\mathbf{8 0})$. Cytokines were measured using Milliplex kit and $\mathrm{T}$ cell reactivity was studied by CFSE dilution. Statistical analysis was performed using SPSS software. Patients with myocardial infarction showed higher proportion of IL-17 expressing CD4+ and CD8+ ${ }^{+}$cells (Th17 and Tc17) and elevated levels of IL-6 and IL-17 in plasma with significant reduction in circulating Tregs. Th1, Th2 and $\mathrm{CD}^{+}{ }^{+} \mathrm{CD}^{28}{ }^{\text {null }}$ cells were not significantly different in patients compared to healthy individuals. The ratio of Th17 and Tc17 to Tregs showed an independent association with STEMI with an adjusted odds ratio of 2.92 (95\% CI: 1.73 - 4.92), $\mathrm{P}<0.001$ and 2.22 (95\% CI: 1.42 - 3.44), $\mathrm{P}<0.001$ respectively. Reactivity to HSP60 and oxidized LDL with expansion of IL-17 expression was higher in patients compared with control. Young patients ( $<45$ years) with no apparent risk factor could be distinguished from healthy controls by the increase in Th17 and ratio of Th17 and Tc17 to Tregs in peripheral blood. Conclu-

\footnotetext{
"Corresponding author.
} 
sion: Our results suggest that an imbalance in both $\mathrm{CD4}^{+}$and $\mathrm{CD8}^{+} \mathrm{T}$ cells secreting IL-17 and Tregs is associated with acute myocardial infarction. HSP60 and Ox-LDL may contribute to this response and pathogenesis of AMI in Indian population.

\title{
Keywords
}

\author{
T Lymphocytes, Adaptive Immunity, Coronary Artery Disease, Myocardial Infarction, Cytokines, \\ Auto-Antigens
}

\section{Introduction}

Coronary artery disease (CAD) is the most significant cause of global mortality despite advances in medicine and drug development [1]. Atherosclerosis is now accepted as a chronic autoimmune inflammatory disease, based on our increased understanding of the role of immune system in the disease pathology [2]. T lymphocytes are involved in the initiation, progression and destabilization of atherosclerotic lesions and are demonstrated in the atherosclerotic plaques from humans and experimental animals [3]-[6]. Inflammatory $\mathrm{T}$ cell response to lipoproteins, heat shock proteins and molecular mimicry with microbial antigens is believed to initiate the autoimmune reactions during atherogenesis [7]. The T helper (Th) cell-1 and the Th17 cells contribute to the pro atherogenic $\mathrm{T}$ cell response while the influence of Th2 cells on atherosclerosis is inconsistent. Regulatory T cells (Tregs) are known to suppress the inflammatory response and have a protective role in atherosclerosis [8].

Naturally occurring Treg cells, characterized by the intracellular expression of fox head transcription factor $\left(\mathrm{CD} 4^{+} \mathrm{CD} 25^{+} \mathrm{Foxp}^{+}\right)$, maintain the immune homeostasis and suppress the inflammatory immune response [9]. Reduction in Tregs and their activity is seen in inflammatory and autoimmune diseases [10]. In contrast, the Th17 cells play a critical role in the pathology of allergy and autoimmune response [11]. Since these two cell types have an opposite effect on the immune response, and their balance is important in the development of autoimmune and inflammatory diseases. [12]-[14]

Earlier studies have shown increased frequency of circulating pro inflammatory T cells secreting IL-17 and IFN- $\gamma$ and a reduction in the number of naturally occurring Tregs with compromised suppressive properties in MI patients [15]-[20]. Cheng et al. showed that Th17/Treg balance controls inflammation and may be important in the pathogenesis of plaque destabilization and the onset of acute coronary syndrome [15]. Imbalance in Th17/ Treg was also found to be associated infarction related cardiogenic shock [21]. Apart from Th17 Treg imbalance, patients with unstable angina were reported to have an increased frequency of $\mathrm{CD}^{+} \mathrm{CD}^{-} 8^{-} \mathrm{T}$ lymphocytes which secrete high level of IFN- $\gamma$ and perforin [22] [23]. CD4 T cells have been the focus of attention in most of the clinical studies while the CD8 subpopulation has been less investigated.

Although several studies have shown differences in the circulating $\mathrm{T}$ cells in independent populations, the mechanism and the cause of skewed balance in T lymphocyte subsets in the peripheral circulation are not known. Asian Indian population belongs to a high risk group for developing atherothrombotic disease, which is not explained by the conventional risk factors alone [24]. High frequency of diabetes and insulin resistance, high body fat, elevated levels of fibrinogen, homocysteine, and plasminogen activator, low HDL, and higher incidence of infection and inflammation are some of the factors which can contribute to the higher prevalence of the disease in this population [25]. Many of these factors have a direct influence on the immune system and the circulating lymphocytes. The profiles of circulating lymphocytes have not been explored in this population so far. In the present study, we investigated the independent contributions of specific T cell subsets including the $\mathrm{CD} 4^{+}$and $\mathrm{CD}^{+} \mathrm{T}$ lymphocytes with intracellular expression of IFN- $\gamma$, IL-17, IL-4 and Treg to myocardial infarction, and correlated serum cytokine levels and antigen reactivity to the T cells in an attempt to understand the role of specific $\mathrm{T}$ lymphocytes in atherosclerosis and atherothrombosis

\section{Methods}

\subsection{Study Population}

The investigation conforms to the principles outlined in the Declaration of Helsinki and guidelines approved by 
Indian council of medical research (ICMR, India). The study was approved by the Institutional ethics committees of Thrombosis research Institute and Narayana Hrudayalaya hospital. An informed consent was taken from all the participants prior to enrolment. The study population included patients admitted to the Narayana Hrudayalaya hospital between October 2012 and April 2014, with no previous report of cardiac problem. Patients with acute myocardial infarction with elevation of ST segment and increase in cardiac troponin I were classified as STEMI. Samples were collected within 24 - 48 hrs from the onset of event. Age and gender matched healthy volunteers without any clinical symptoms of CAD, and with normal ECG were enrolled as controls for the study. Exclusion criteria included presence of any major illness as defined by world health organization (known primary myocardial disease, presence of congenital heart disease or contagious diseases. Individuals with family history of CAD were excluded from the study. A standardized questionnaire was used to record history of hypertension, diabetes mellitus, smoking, body mass index, waist hip ratio and medication. Resting blood pressure, fasting blood glucose levels, ECG and angiogram records (only for patients) were obtained for all the participants. Subjects were considered as active smokers if they were current smokers or had stopped smoking within a month before entry into the study. Subjects with high fasting blood sugar levels $>7 \mathrm{~mm} / \mathrm{litre}(125 \mathrm{mg} / \mathrm{dL})$ were categorized as hyperglycemic.

\subsection{Flow Cytometry}

Peripheral blood mononuclear cells (PBMCs) are isolated using Ficoll (Histopaque-Sigma Chemicals, USA) density gradient centrifugation from venous blood samples. PBMCs were activated for 4 hours with phormalmyristate acetate $(10 \mathrm{ng} / \mathrm{ml})$ and ionomycin $(1 \mu \mathrm{g} / \mathrm{ml})$ in the presence of $100 \mathrm{ng} / \mathrm{ml}$ Brefeldin (Sigma Chemicals, St. Louis, USA). Surface staining was performed by using anti CD3 and anti CD4 antibodies conjugated to Allophyocyanin $\mathrm{H7}$ and Fluorescein isothiocyanate respectively for 20 minutes at room temperature. Intracellular staining was carried out with Peridinin chlorophyll Cy5.5 conjugated anti IL-4, Phycoerythrin conjugated anti IL-10, Allophyocyanin conjugated anti IL-17 and PE CY7conjugated anti IFN- $\gamma$. For regulatory T cell staining, Allophyocyanin conjugated CD25 and Phycoerythrin conjugated anti human FOX P3 were used in a separate tube along with CD3 and CD4 as mentioned earlier (Allantibodies were from BD Biosciences, CA, USA). Samples were acquired using FACS Canto II flow Cytometer using FACS Diva software (Becton Dickinson, NJ, USA). Fluorescence minus one and unstained control were used for setting the gates. FLOWJO Version 7.6.5 (Tree star Ltd., Oregon, USA) was used for data analysis and results were expressed as a percentage of CD4 $4^{+} \mathrm{T}$ cells by sequential gating on lymphocytes (Figure 1). Detailed description of flow cytometry is given in supplementary methods.

\subsection{Cell Proliferation Assays}

Cell proliferation experiments were performed in Rosewell Park Memorial Institute (RPMI) 1640 medium (Bio Whittaker, Walkersville, MD, USA) supplemented with $10 \%$ AB serum, $2 \mathrm{mM}$ glutamine, $10 \mathrm{mM}$ HEPES (4-(2-hydroxyethyl)-1-piperazineethanesulfonic acid), sodium pyruvate, and antibiotics. T cell proliferation was monitored by the reduction in 5, 6-carboxyfluorescein diacetate succinimidyl ester (CFSE) fluorescence in the CD3positive cells for 3 days [26] [27]. PBMCs $\left(10^{7} / \mathrm{ml}\right)$ were labeled with $10 \mu \mathrm{M}$ CFSE (Sigma Chemicals, USA) and activated with antigens $(10 \mu \mathrm{g} / \mathrm{mL})$. Purified ApoB100, HSP60 and human LDL were purchased from Sigma chemicals, St. Louis, USA. LDL was oxidized overnight with CuSO4 (5 $\mu \mathrm{M})$ to get copper oxidized LDL (Ox-LDL) [28]. Phytohaemagglutinin (PHA) and unstimulated cells were used as positive and negative control respectively. Cells were re stimulated with same antigen in the presence of $100 \mathrm{ng} / \mathrm{ml}$ Brefeldin for the last 4 hours of culture [29]. After 72 hours of incubation, cells were stained with anti-CD3-PE (UCHT1e Biosciences, clone, California, USA), anti IL-17-APC and PE CY 7anti IFN- $\gamma$ (BD Biosciences, CA, USA) and analyzed by flow cytometry as described earlier. Lymphocytes were gated using forward and side-scatter plots. Proliferation of T cells was measured by CFSE dilution using FACS CANTO II (Becton Dickinson, New Jersey, USA) and analyzed using FlowJO software. The proliferation index of T cells was calculated from the FlowJO software. Proliferation index of test wells were divided by that of control wells without antigen for analysis [30].

\subsection{Measurement of Cytokines}

Cytokines, interleukin (IL)-4, IL-5, IL-6, IL-10, IL-17, and interferon $\gamma$ (IFN- $\gamma$ ), were measured using the 


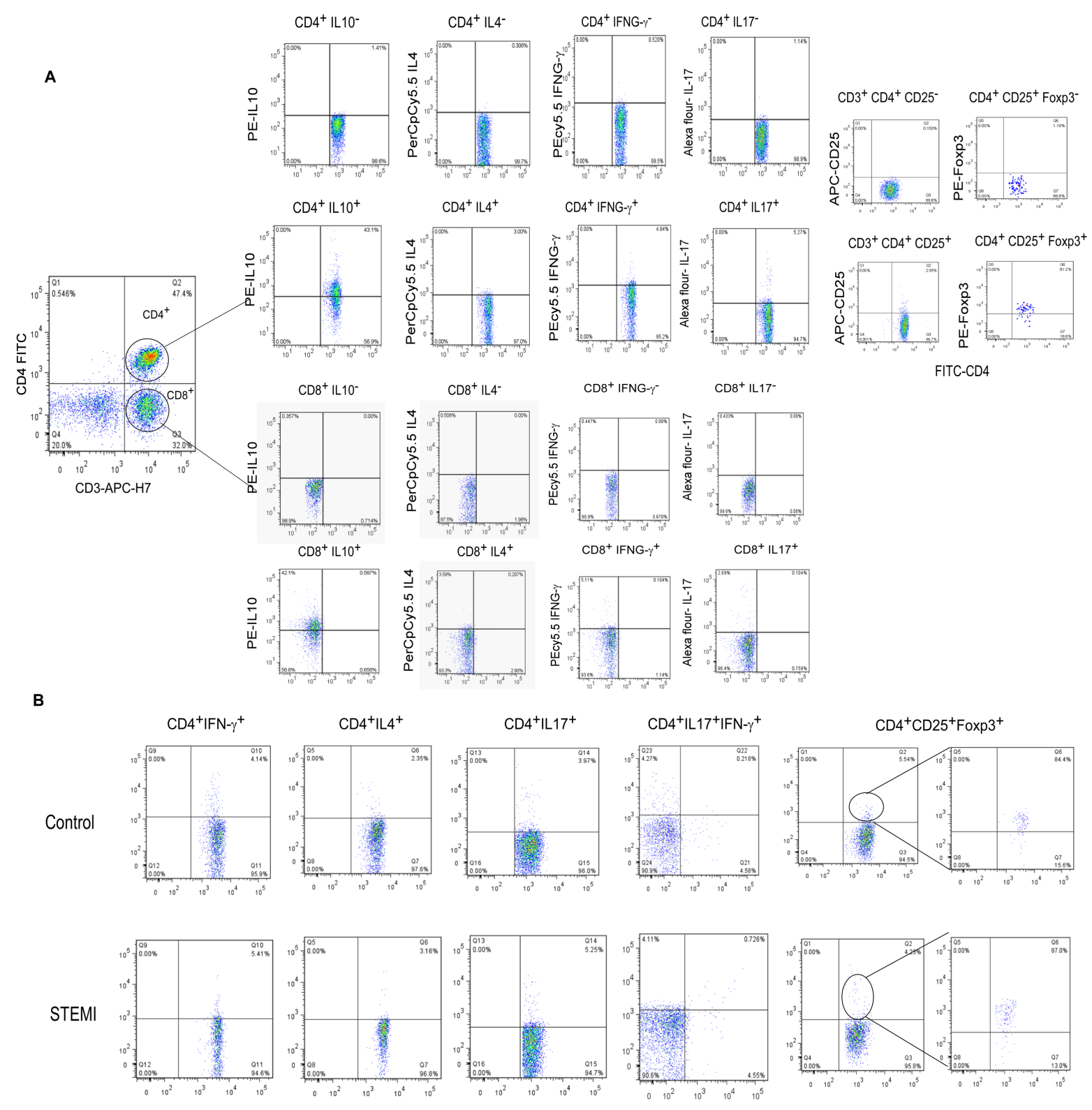

Figure 1. Flow cytometry analysis. (A): Gating strategy followed for Sequential analysis of Lymphocyte population by flow cytometry: Representative dot plot showing lymphocytes from peripheral blood mononuclear cells. PBMCs were gated on forward and side scatter to identify the lymphocyte population. The lymphocytes were further gated as CD3 and CD4 positive cells. Fluorescent minus control for each cytokine antibody was used to gate for the cytokine expression. Fluorescent minus control for $\mathrm{CD} 25$ was used to get the $\mathrm{CD} 3^{+} \mathrm{CD} 4{ }^{+} \mathrm{CD} 25^{+}$positive cells. Intracellular expression of Foxp3 was determined in these cells. The numbers of $\mathrm{CD} 4{ }^{+} \mathrm{CD} 25^{+} \mathrm{Foxp}^{+}$cells were calculated as percentage of CD4 positive cells. (B): Representative dot plots of distribution of $\mathrm{T}$ cell subsets across MI Patients and Control. The quantitative data is given in Table 2.

MILLIPLEX (MAP-plex) Cytokine Kit (Millipore, Billerica, MA) at the Millipore Service facility (Bangalore, India). Lipid concentrations were determined on the Cobas Fara II Clinical Chemistry auto analyzer (F. Hoffman La Roche Ltd., Basal, Switzerland), following the manufacturer’s instructions.

\subsection{Statistical Analysis}

Quantitative data were tested for normality using Kolmogorov-Smirnov test and were transformed using natural 
logarithms wherever a deviation from normality was observed (lipids levels, BMI, WHR and cytokine levels). Percentage data was arcsine transformed for analysis [31]. The qualitative and categorical data were analyzed using frequencies/proportions using Chi-square tests and quantitative data was compared by independent $\mathrm{T}$ test. The $\mathrm{T}$ cell sub types were compared using multivariate analysis using age, gender, current smoking, diabetes, hyperglycaemia and hypertension as covariates. The odds ratios (ORs) and their 95\% confidence interval (CI) were determined for each $\mathrm{T}$ cell subset using binary logistic regression analysis. Those variables that had shown significant mean difference were taken for the regression analysis by taking the classical risk factors (age, gender, hypertension, diabetes, hyperglycaemia, current smoking, waist hip ratio and body mass index) as covariates. The Receiver Operating Characteristic (AUC) analysis and C-Statistics were computed to understand the improvement in predictive probability of the $\mathrm{T}$ cell subsets in addition to classical risk factors in a multivariable model. The change in AUC and its significance was calculated using DeLong method (Med Calc statistical software http://www.medcalc.org/). All statistical analyses were performed using SPSS version 17.0 for Windows and $p$ value $<0.05$ was considered statistically significant.

\section{Results}

\subsection{Demographic Characteristics}

Baseline demographic characteristics of STEMI patients compared to age and gender matched controls is given in Table 1. The mean age of the study population was $47.5 \pm 7.0$. The prevalence of hypertension, diabetes, and smoking were higher in patients compared to controls. Hyperglycaemia was highly prevalent in the population. Although only 7 controls (8.8\%) were diagnosed as diabetic and were under treatment, 25 (31\%) of them had higher fasting glucose levels ( $>125 \mathrm{mg} / \mathrm{dl})$. Amongst patients, 29 (36.7\%) had known history of diabetes however, 54 (68.4\%) were hyperglycaemic. Lipid levels, body mass index and waist hip ratio were comparable between patients and control. ACE inhibitors as anti hypertensive treatment and aspirin and statin therapy were frequently used in patients. More than one vessel was affected in $21.5 \%$ in patients.

Table 1. Baseline characteristics.

\begin{tabular}{ccc}
\hline Variables & Control (N = 79) & STEMI (N = 80) \\
Age (years) & $46.79(7.2)$ & $47.52(7.0)$ \\
Male (\%) & $74(92.5)$ & $75(94.9)$ \\
Diabetes N (\%) & $7(8.8 \%)$ & $29(36.7 \%)^{* * *}$ \\
Hyperglycaemia (\%) & $25(31.3 \%)$ & $54(68.4 \%)^{* * *}$ \\
Hypertension N (\%) & $4(5.0 \%)$ & $21(26.6 \%)^{* * *}$ \\
Current Smoking N (\%) & $18(22.5 \%)$ & $30(38.0 \%)^{*}$ \\
BMI-Mean (SD) & $25.29(3.45)$ & $25.38(4.06)$ \\
WHR-Mean (SD) & $0.92(0.05)$ & $0.92(0.04)$ \\
TC-Mean (95\% CI) & $4.64(3.84-5.59)$ & $4.23(3.33-5.38)^{*}$ \\
TG-Mean (95\% CI) & $1.67(0.91-3.05)$ & $1.55(0.89-2.71)$ \\
SBP-Mean (SD) & $128.90(15.48)$ & $114.18(15.82)^{* * * *}$ \\
DBP-Mean (SD) & $84.58(11.28)$ & $75.14(10.54)^{* * *}$ \\
FBS-Mean (SD) & $6.45(2.29)$ & $9.04(4.42)^{* * *}$ \\
LDL-Mean (95\% CI) & $2.75(1.97-3.84)$ & $2.54(1.80-3.59)$ \\
HDL-Mean (95\% CI) & $0.88(0.68-1.13)$ & $0.81(0.59-1.08)$ \\
Beta-blockers N (\%) & NA & $54(70.1 \%)$ \\
ACE inhibitors N (\%) & NA & $36(46.8 \%)$ \\
Statin N (\%) & NA & $71(92.2 \%)$ \\
Aspirin N (\%) & NA & $71(92.2 \%)$ \\
>1 Affected vessel N (\%) \% & NA & $17(21.5 \%)$ \\
\hline
\end{tabular}

Values are represented as percentage or as Mean (SD-standard deviation) and as Mean (95\% CI) for variables which were log transformed for analysis. Lipid and sugar levels are expressed in mMol/L. BMI: Body mass index, WHR: Waist hip ratio, SBP: Systolic blood pressure, DBP: Diastolic blood pressure, TC: Total cholesterol, TG: Triglycerides, LDL: Low density lipoprotein, HDL: High density lipoprotein. ${ }^{*} \mathrm{P}<0.01,{ }^{* * *} \mathrm{P}<0.001,{ }^{* * *} \mathrm{P}<$ 0.0001 . 


\subsection{Frequency of Circulating T Cell Sub Population and Plasma Cytokines Patients and Control}

STEMI patients showed an increase in $\mathrm{CD}^{+}$and $\mathrm{CD} 8^{+}$cells expressing IL-17, $(\mathrm{P}<0.001)$, and $\mathrm{CD} 4^{+}$cells double positive for IL-17 and IFN- $\gamma(\mathrm{P}=0.048)$, while regulatory T cells of the phenotype $\mathrm{CD}^{+} \mathrm{CD}^{+} 5^{+} \mathrm{Foxp}^{+}$ were significantly lower $(\mathrm{P}=0.017)$ in patients compared to control. The ratio of Th17 cells to Treg $(\mathrm{P}<0.001)$, Tc17 to Treg $(\mathrm{P}<0.001)$, Th1 to Treg $(\mathrm{P}=0.014)$ and that of Th17 to Th2 $(\mathrm{p}=0.028)$ were significantly higher in patients. We did not observe any significant difference in the frequency of $\mathrm{CD} 4{ }^{+} \mathrm{CD} 28^{-}$cells and Th1 cells between patient and controls (Table 2, Figure 1). Serum levels of IL-17 $(P=0.027)$ and IL-6 $(P=0.001)$ were found to be higher in patients compared to control (Table 2). We were not able to detect a significant correlation between serum cytokine concentration and $\mathrm{T}$ cell frequency (data not shown).

Table 2. Frequency of $\mathrm{T}$ cell sub population and plasma cytokine levels in patients and control.

\begin{tabular}{|c|c|c|c|c|}
\hline Variable & Control $(N=79)$ & STEMI $(\mathbf{N}=\mathbf{8 0})$ & $\begin{array}{c}\text { P value } \\
\text { Model } 1\end{array}$ & $\begin{array}{l}\text { P value } \\
\text { Model } 2\end{array}$ \\
\hline CD4 & $37.13(27.28$ - 47.56) & $37.68(27.47$ - 48.48) & NS & NS \\
\hline CD8 & 34.99 (25.66 - 44.94) & $32.42(23.48-42.07)$ & NS & NS \\
\hline CD4/CD8 & $1.13(0.64-1.75)$ & $1.25(0.65-2.04)$ & NS & NS \\
\hline $\mathrm{CD} 4^{+} \mathrm{IFN} \gamma^{+}$(Th1) & $3.87(1.85-6.58)$ & $4.61(2.83-6.79)$ & NS & NS \\
\hline $\mathrm{CD}^{+} \mathrm{IL}^{-} 4^{+}$(Th2) & $3.00(1.93-4.32)$ & $3.45(2.07-5.16)$ & 0.046 & NS \\
\hline $\mathrm{CD}^{+} \mathrm{IL}^{-17^{+}}$(Th17) & $3.72(2.34-5.41)$ & $5.07(3.03-7.60)$ & $<0.001$ & $<0.001$ \\
\hline $\mathrm{CD} 4^{+} \mathrm{IL}-10^{+}$ & $50.13(28.94-71.30)$ & $54.39(35.72-72.44)$ & NS & NS \\
\hline $\mathrm{CD}^{+} \mathrm{CD}_{25}^{+}$ & $5.47(3.42-7.96)$ & $4.79(3.00-6.98)$ & 0.043 & NS \\
\hline $\mathrm{CD}^{+} 25^{+}$Foxp $^{+}$(Treg) & $3.78(2.17-5.82)$ & $3.07(1.78-4.69)$ & 0.006 & 0.017 \\
\hline $\mathrm{CD}^{+} \mathrm{CD} 28^{-}$ & $3.13(0.92-6.82)$ & $4.26(0.55-6.80)$ & NS & NS \\
\hline $\mathrm{CD}^{+} \mathrm{IL}^{-} 4^{+} \mathrm{IL}-10^{+}$ & $1.74(0.71-3.21)$ & $2.13(0.95-3.77)$ & NS & NS \\
\hline $\mathrm{CD} 4^{+} \mathrm{IL}-17^{+} \mathrm{IFN} \gamma^{+}$ & $0.27(0.06-0.64)$ & $0.41(0.09-0.95)$ & 0.020 & 0.048 \\
\hline Th17/Treg & $1.11(0.52-1.71)$ & $2.08(0.51-3.65)$ & $<0.001$ & $<0.001$ \\
\hline Th1/Treg & $1.27(0.34-2.19)$ & $1.88(0.67-3.09)$ & 0.001 & 0.014 \\
\hline Th17/Th2 & $1.43(0.661-2.26)$ & $1.82(0.44-3.20)$ & 0.044 & 0.028 \\
\hline Th1/Th2 & $1.50(0.41-2.60)$ & $1.55(0.61-2.48)$ & NS & NS \\
\hline $\mathrm{CD}^{+} \mathrm{IFNG}^{+}(\mathrm{TC} 1)$ & $3.16(1.25$ - 5.89) & $3.36(1.50-5.91)$ & NS & NS \\
\hline $\mathrm{CD}^{+} \mathrm{IL}^{-} 4^{+}$(Tc2) & $2.29(0.92-4.26)$ & $2.75(1.17-5.01)$ & NS & NS \\
\hline $\mathrm{CD}^{+} \mathrm{IL}^{-17^{+}}$(Tc17) & $3.77(2.03-6.01)$ & $4.95(2.89-7.52)$ & 0.001 & 0.004 \\
\hline $\mathrm{CD}^{+} \mathrm{IL}^{-10^{+}}$ & $50.01(28.88$ - 71.15) & $51.03(30.75$ - 71.14) & NS & NS \\
\hline Tc17/Treg & $1.16(0.51-1.80)$ & $2.11(0.37-3.84)$ & $<0.001$ & $<0.001$ \\
\hline IFN- $\gamma$ & 18.77 (11.87 - 29.69) & $19.18(9.08$ - 40.52) & NS & NS \\
\hline IL-4 & $47.06(21.23-104.35)$ & $34.42(13.92-85.11)$ & NS & NS \\
\hline IL-5 & $3.58(1.65-7.76)$ & $3.78(1.77-8.06)$ & NS & NS \\
\hline IL-17 & $10.86(6.53-18.07)$ & 13.87 (6.97 - 27.61) & 0.097 & 0.027 \\
\hline IL-6 & $14.82(8.31$ - 26.42) & $22.30(11.36$ - 43.79) & 0.004 & $<0.001$ \\
\hline IL-10 & $9.50(4.45-20.27)$ & $8.08(3.36-19.41)$ & NS & NS \\
\hline
\end{tabular}

Values are represented as Mean (95\% CI). Multivariate analysis of covariance (MANCOVA) was used to compare the mean values. In Model 1 age and gender, were taken as covariates and in Model 2 age, gender, hypertension, diabetes and smoking were taken as covariates. Gating strategy used to identify the different population is given in Figure 1. Cytokine levels in serum were measured using Milliplex-Cytomax kit. IL: Interleukin, IFN: Interferon. 
Gating strategy followed for Sequential analysis of Lymphocyte population by flow cytometry: Representative dot plot showing lymphocytes from peripheral blood mononuclear cells. PBMCs were gated on forward and side scatter to identify the lymphocyte population. The lymphocytes were further gated as CD3 and CD4 positive cells. Fluorescent minus control for each cytokine antibody was used to gate for the cytokine expression. Fluorescent minus control for $\mathrm{CD} 25$ was used to get the $\mathrm{CD}^{+} \mathrm{CD} 4^{+} \mathrm{CD} 25^{+}$positive cells. Intracellular expression of Foxp3 was determined in these cells. The numbers of $\mathrm{CD} 4^{+} \mathrm{CD} 25^{+} \mathrm{Foxp}^{+}$cells were calculated as percentage of CD4 positive cells.

B: Representative dot plots of distribution of T cell subsets across MI Patients and Control. The quantitative data is given in Table 2.

\subsection{Risk Association of T Cell Markers and Plasma Cytokines with Myocardial Infarction}

Logistic regression analysis showed a significant association between Th17 (OR: 135, 95\% CI: 1.14 - 1.61, P < 0.001 ) and Tc17 (OR: 1.20, 95\% CI: $1.04-1.38, \mathrm{P}=0.009)$ cells in circulation with STEMI. The ratio of Th17 to Treg cells and that of Tc17 to Treg were also significantly associated with STEMI (OR: 2.92, 95\% CI: 1.73 4.92, P < 0.001 and OR: 2.22, 95\% CI: $1.42-3.94, \mathrm{P}<0.001$ ) respectively. Th1/Treg ratio also showed a positive association with an odds ratio of 1.58, 95\% CI: $1.10-2.29, \mathrm{P}=0.014)$. The frequency of Treg cells $\left(\mathrm{CD}^{+} \mathrm{Foxp}^{+}\right)$was a protective marker with a protective ratio of (OR: 0.83, 95\% CI: $0.71-0.97, \mathrm{P}=0.026$ ) (Table 3).

To assess the sensitivity of the $\mathrm{T}$ cell markers in discriminating the patients from control population in the logistic regression models, we assessed the Area under the Receiver Operating Characteristic (ROC) curve (AUC or C statistics). Incorporation of T cell markers to classical risk factors (age, gender, BMI, WHR, Diabetes, hyperglycaemia, hypertension and current smoking) significantly increased the AUC values. The increase was highest for Th17/Treg ratio (0.049), but this change in area under the curve was not found to be significant (Figure 2).

Logistic regression analysis was carried out by taking the markers as continuous variable. Classical risk factors, (Age, gender, body mass index, waist hip ratio, hypertension, diabetes, hyperglycaemia, LDL and current smoking) were taken as covariates. The Receiver Operating Characteristic (AUC) analysis and C-Statistics were computed to understand the improvement in predictive probability of the $\mathrm{T}$ cell subsets in addition to classical risk factors in a multivariable model. The change in AUC and its significance was calculated using De long test. AUC: area under the curve, CI: confidence interval, OR: odds ratio. The ROC curves are represented in Figure 2.

The Receiver Operating Characteristic (AUC) analysis and C-Statistics were computed to understand the improvement in predictive probability of the $\mathrm{T}$ cell subsets in addition to classical risk factors in a multivariable model. The change in AUC and its significance was calculated using De long test. AUC: area under the curve, CI: confidence interval, OR: odds ratio.

\subsection{Adaptive Response to Self Antigens}

Inflammatory immune response apolipoprotein B (ApoB) 100, heat shock protein (HSP) 60 and modified LDL are known to have a critical role in atherosclerosis. To understand the role of immune response to these antigens in inflammation associated with CAD, we compared the response of $\mathrm{T}$ cells from patient and control to these antigens to understand the differential immune response in these subjects. T cell proliferation as assessed by CFSE

Table 3. Association and C statistics of T cell markers with STEMI.

\begin{tabular}{|c|c|c|c|c|}
\hline Marker & OR (95\% CI), p Value & AUC (95\% CI), & Z Statistics & $\begin{array}{c}\text { P value for } \\
\text { change }\end{array}$ \\
\hline Risk Factors & & $0.787(0.715-0.849)$ & & \\
\hline Th17 & $1.35(1.14-1.61),<0.001$ & $0.817(0.747-0.874)$ & 1.21 & 0.225 \\
\hline Tc17 & 1.20 (1.04 - 1.38), 0.009 & $0.804(0.733-0.864)$ & 0.91 & 0.363 \\
\hline Treg & 0.83 (0.71 - 0.97), 0.026 & $0.800(0.728-0.860)$ & 0.76 & 0.447 \\
\hline Th17/Treg & $2.92(1.73-4.92),<0.001$ & $0.836(0.768-0.891)$ & 1.86 & 0.061 \\
\hline Tc17/Treg & 1.58 (1.10 - 2.29), 0.014 & $0.793(0.720-0.854)$ & 0.30 & 0.761 \\
\hline Th1/Treg & $2.22(1.42-3.44),<0.001$ & $0.891(0.749-0.877)$ & 1.54 & 0.121 \\
\hline
\end{tabular}



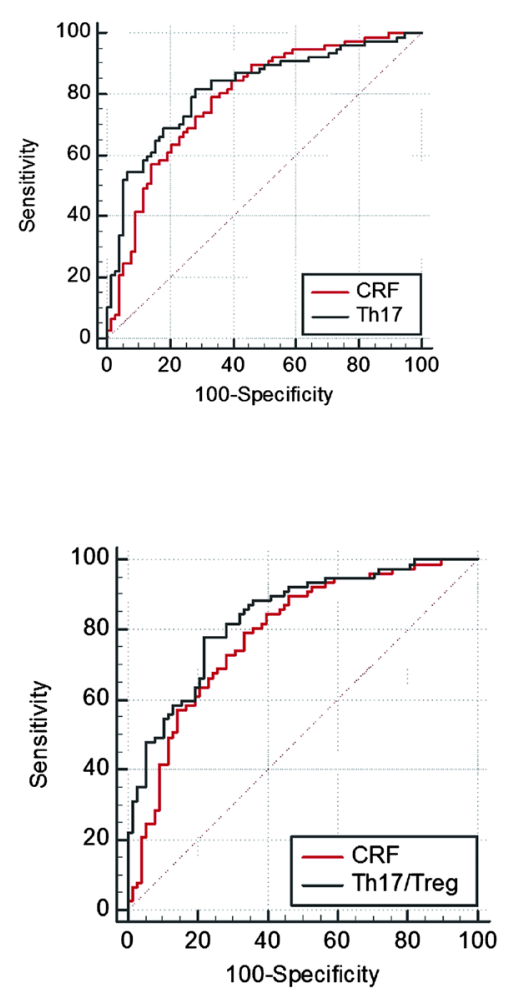
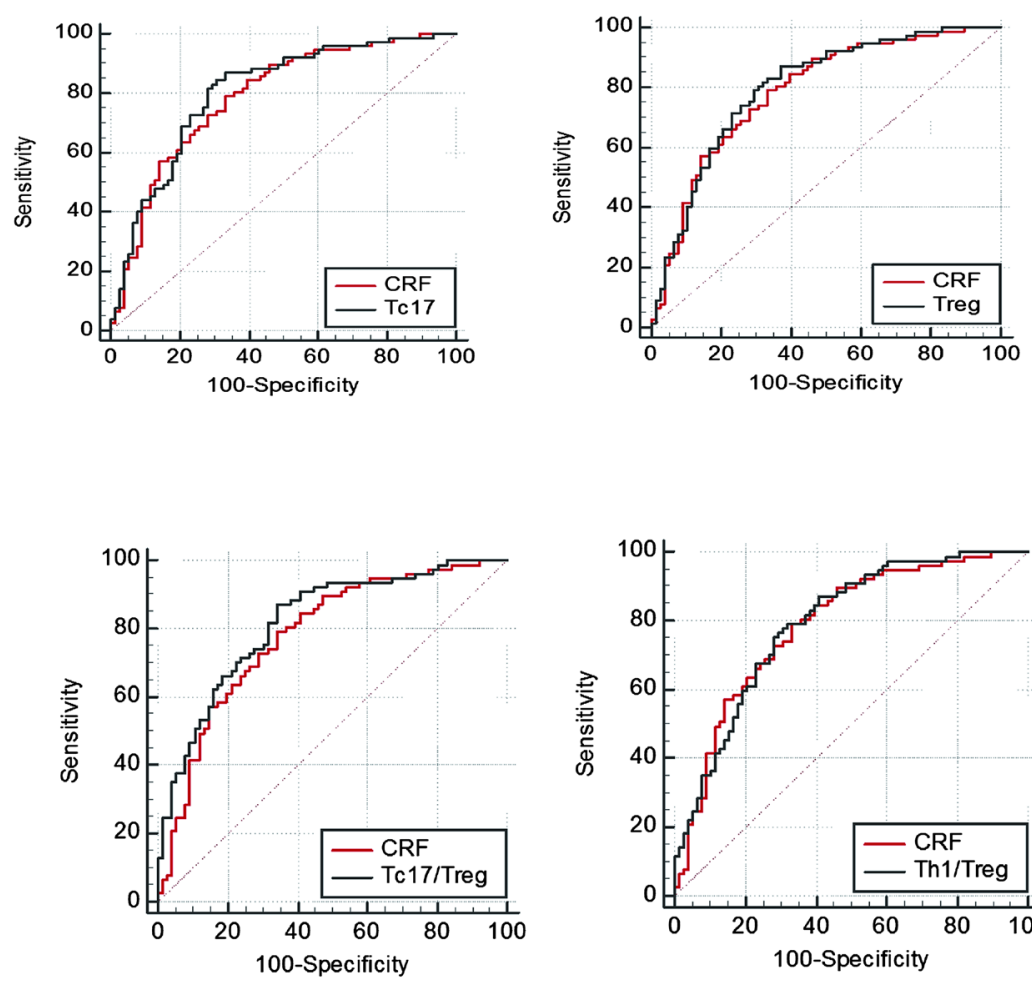

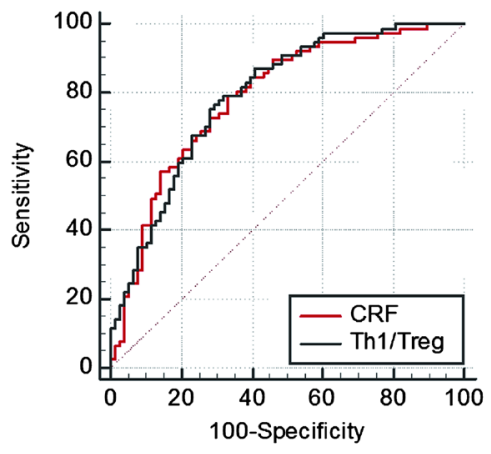

Figure 2. Association of circulating T cell markers and cytokine concentration with STEMI. The Receiver Operating Characteristic (AUC) analysis and C-Statistics were computed to understand the improvement in predictive probability of the T cell subsets in addition to classical risk factors in a multivariable model. The change in AUC and its significance was calculated using De long test. AUC: area under the curve, CI: confidence interval, OR: odds ratio.

dilution in CD3 positive cells was significantly higher in patients for oxidized LDL $(1.27 \pm 0.06$ vs. $0.84 \pm 0.11$, $\mathrm{P}=0.015$ ) and HSP60 protein (1.62 \pm 0.71 vs. $0.75 \pm 0.21, \mathrm{P}=0.004$ ) compared to healthy control (Figure 3 ). Proliferating $\mathrm{T}$ cells from STEMI were found to express significantly higher intracellular IL-17 in response to HSP60 and Ox-LDL as observed by flow cytometry ( $\mathrm{P}=0.02$ and 0.01 respectively) (Figure 3).

\subsection{Comparison of Young and Older Patients with Myocardial Infarction}

Young Indians are known to have a higher susceptibility for acute MI. To understand if the immune markers can distinguish these susceptible individuals, we divided the study population into two groups of age group less than 45 years $(\mathrm{N}=33)$ and more than 45 years $(\mathrm{n}=46)$. In young STEMI patients ( mean age:40.6 \pm 3.74 years), the classical risk factors including diabetes, hypertension, lipid levels, BMI and smoking were comparable with control, while in older patients( mean age: $52.43 \pm 4.0$ years), we observed a significant increase in occurrence of diabetes, hypertension and smoking. Hyperglycaemia was significantly higher in both young and older patients. Most of the young patients had a single vessel disease (93.94\%) while multiple vessels were affected in $32.6 \%$ of older patients. Th17 $(\mathrm{P}<0.001)$ cells and the ratio of Th17/Treg $(\mathrm{P}<0.005)$ and Tc17/Treg $(\mathrm{P}<0.01)$ were higher in both young and older patients compared to control. In the older patients Tc17 cells $(P=0.006)$ were also higher, which was not significant in young patients. The numbers of circulating Tregs were lower in patients but were not statistically significant. Plasma IL-6 levels were significantly higher in young patients $(\mathrm{P}=$ 0.01). No difference was observed in the concentration of other cytokines tested (Table 4).

\subsection{Risk Association of Classical Risk Factors, T Cell Markers with Myocardial Infarction in Young and Older Patients}

We then compared the risk association of classical risk factors and T cells with MI in young and older MI patients. Hypertension and Diabetes contributed to significant risk in older MI patients but was not a significant 

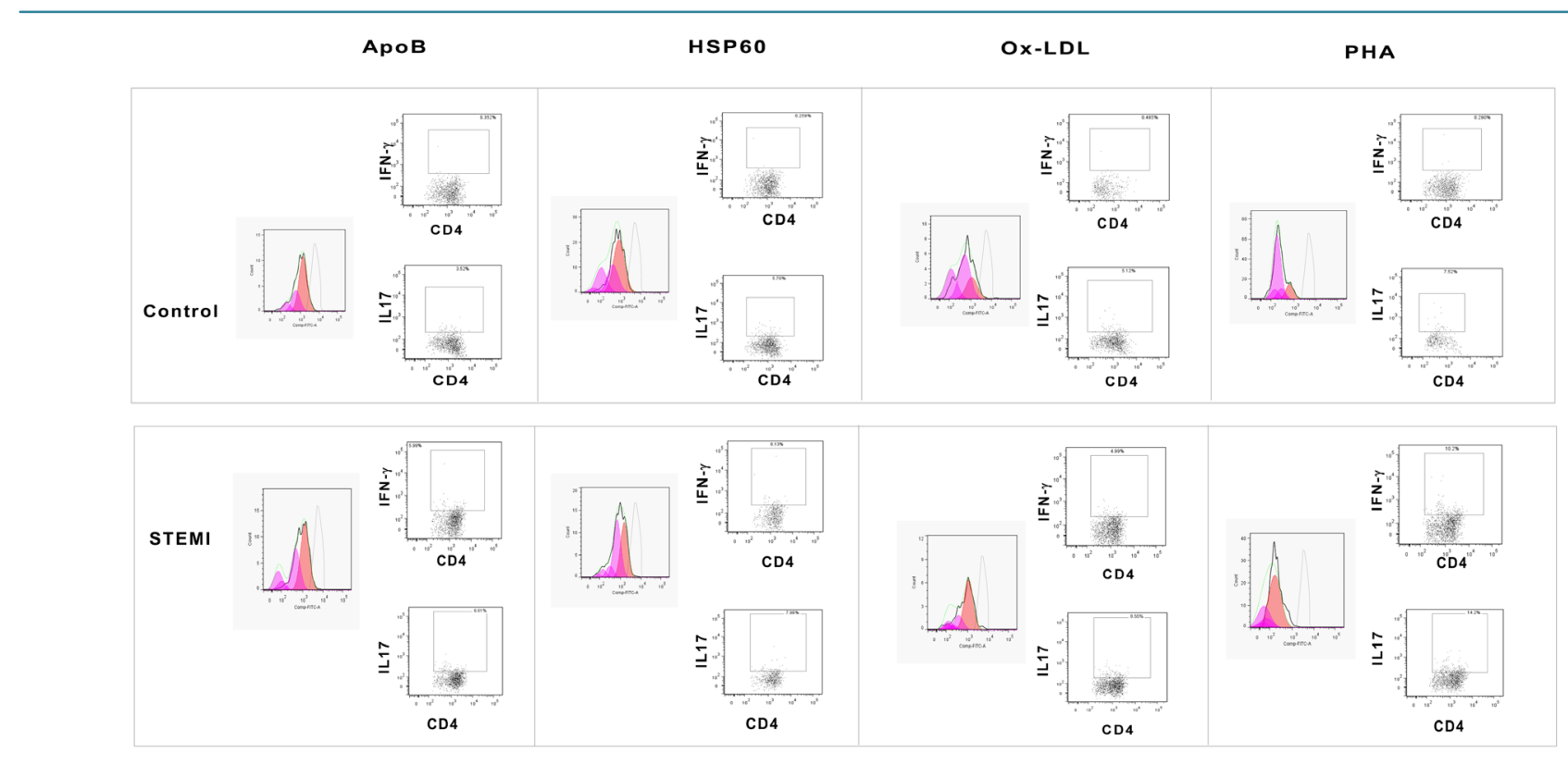

Аров
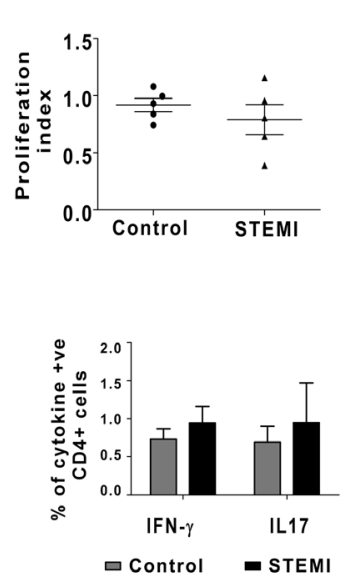

HSP60

(a)

OX-LDL
PHA
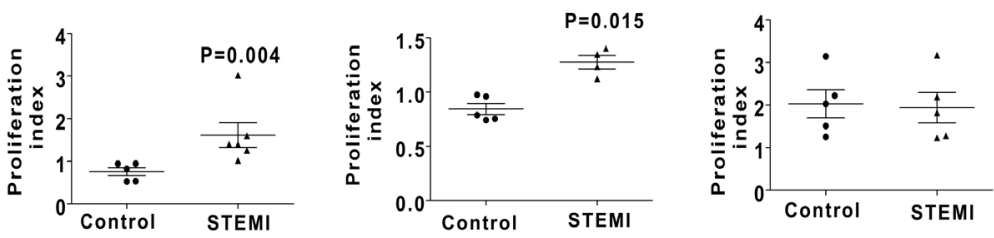

(b)
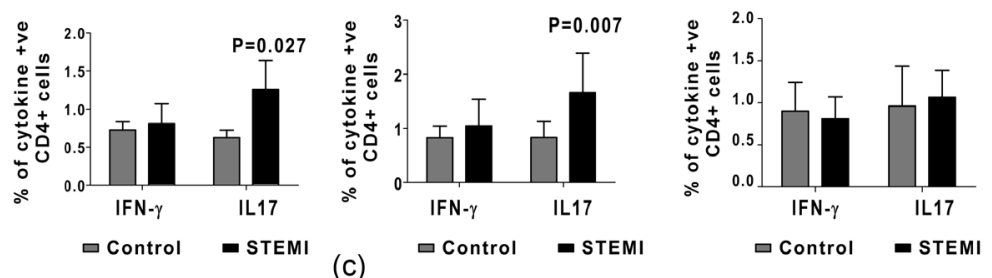

(c)

Figure 3. Reactivity of T cells to self antigens and intracellular expression of IL-17 and IFN- $\gamma$ in antigen activated T cells. (a): Representative data showing T cell proliferation as determined by CFSE dilution and flow cytometry data showing intracellular staining of IFN- $\gamma$ and IL-17 in proliferating cells. Gating strategy was followed as per Figure 1 . Proliferation of CFSE labelled PBMC in response to Apolipoprotein (Apo) B 100 protein, Heat shock protein (HSP) 60, oxidized low density lipoprotein, (Ox-LDL), and phytohaemagglutinin (PHA) were assessed in from control and STEMI patients. Proliferation of T cells is shown by reduction in CFSE fluorescence in CD3 positive cells. CFSE fluorescence of labelled cells is given by a grey histogram. Proliferation index was measured by FlowJo software. Proliferation index of test wells were divided by that of control wells without antigen for analysis. Part of Proliferating T cells were labeled with CD3, CD4, IFN- $\gamma$ and IL-17 for flow cytometry. (b): Quantitative analysis of proliferation and intracellular expression of IFN- $\gamma$ and IL-17 in proliferating cells.

factor in young patients. Hyperglycaemia contributed to significant risk association (OR: 5.87, 95\% CI: 1.47 23.47, $\mathrm{P}=0.012$ ) in young MI patients but was not significant in older patients. Amongst the cellular markers, Th17 (OR: 1.38 95\% CI: 1.03 - 1.84, P = 0.032), Th17/Treg (OR: 2.65, 95\% CI: 1.23 - 5.73, P = 0.013) and Tc17/Treg (OR: 4.76, 95\% CI: 1.05 - 21.27, P = 0.043) showed a significant association with MI in young patients. While for older patients the association for the markers were Th17 (OR: 1.44 95\% CI: $1.11-1.89$, P = 0.007), Tc17 (OR: 1.32, 95\% CI: 1.05 - 1.66, P = 0.018), Th17/Treg (OR: 3.03, 95\% CI: $1.38-6.60, \mathrm{P}=0.005$ ) and Tc17/Treg (OR: 1.59, 95\% CI: 1.14 - 2.22, $\mathrm{P}=0.007$ ) (Table 5). 


\section{Discussion}

The role of adaptive immune response in the pathogenesis of myocardial infarction has been demonstrated by several studies [4] [32]. Activated inflammatory cells are found in the coronary plaques as well as the peripheral circulation in patients with acute coronary syndrome [23] [33]-[35]. Different subsets of CD4 ${ }^{+} \mathrm{T}$ cells are involved in the pathogenesis of atherosclerosis. In the present study patients with MI had a significant increase in peripheral Th17, Tc17 cells, CD4 T cells expressing both IL-17, IFN- $\gamma$ (double positive), Th17 related cytokines (IL-17 and IL-6) and a reduction in circulating regulatory T cells. The ratio of Th17 to Treg and Tc17 to Treg were significantly altered in MI patients. Circulating T cells from patients showed higher reactivity to HSP60 and Ox-LDL, with elevated intracellular expression of IL-17 suggesting that stress and lipids play an important role in atherothrombosis in the Indian population. Most importantly young ( $<45$ years) MI patients with no apparent risk factors showed a significant increase in Th17 cells in circulation and an altered Th17/Treg and T17/ Treg ratio compared to healthy control. These data suggest the existence of an imbalance between IL-17 secreting CD4 and CD8 cells and Treg cells in MI patients and the possible contribution of HSP60 and OX LDL in this imbalance and pathogenesis of the disease.

Th17 cells are derived from naïve $\mathrm{CD}^{+}$cells and produce characteristic inflammatory cytokines like IL-17A,

Table 4. Comparison of baseline characters and cellular markers in young and older STEMI patients.

\begin{tabular}{|c|c|c|c|c|}
\hline \multirow[b]{2}{*}{ Variables } & \multicolumn{2}{|c|}{ Age $<45$ years } & \multicolumn{2}{|c|}{ Age $>45$ years } \\
\hline & Control (N = 36) & STEMI $(\mathrm{N}=33)$ & Control (N = 44) & STEMI $(N=46)$ \\
\hline Age (years) & $39.85(3.62)$ & 40.67 (3.74) & $52.57(3.7)$ & $52.43(4.0)$ \\
\hline Male-\% & $35(97.2)$ & 31 (93.9) & 39 (88.6) & $44(95.4)$ \\
\hline Diabetes-\% & $3(8.3)$ & $9(27.3)$ & $4(9.1)$ & $20(43.5)^{* * *}$ \\
\hline Hyperglycaemia-\% & $7(19.4)$ & $21(63.6)^{* * *}$ & $18(40.9)$ & $33(71.7)^{* * *}$ \\
\hline Hypertension-\% & $2(5.6)$ & $6(18.2)$ & 2 (4.5\%) & $15(32.6 \%)^{* * *}$ \\
\hline Current Smoking-\% & $8(22.2)$ & $11(33.3)$ & 10 (34.5\%) & $19(41.3)^{*}$ \\
\hline BMI & $25.44(3.83)$ & $25.38(3.90)$ & $25.02(3.21)$ & $25.39(4.21)$ \\
\hline WHR & $0.91(0.05)$ & $0.91(0.06)$ & $0.93(0.05)$ & $0.94(0.04)$ \\
\hline TC & $4.61(3.75-5.65)$ & $4.25(3.35-5.38)$ & $4.66(3.91-5.55)$ & $3.77(1.71-8.31)$ \\
\hline TG & $1.75(0.88-3.5)$ & $1.51(0.87-2.62)$ & $1.60(0.94-2.73)$ & $1.59(0.91-2.78)$ \\
\hline LDL & $2.59(1.72-3.90)$ & $2.60(1.84-3.66)$ & $2.89(2.24-3.72)$ & $2.26(1.06-4.84)^{*}$ \\
\hline HDL & $0.89(0.71-1.12)$ & $0.78(0.56-1.09)$ & $0.87(0.67-1.14)$ & $0.82(0.61-1.08)$ \\
\hline$>1$ Affected vessel \% & NA & $2(6.06)$ & NA & 15 (32.6\%) \\
\hline Th1 & $4.00(2.55-3.77)$ & $4.44(2.83-6.38)$ & $3.93(1.73-6.98)$ & $4.78(2.85-7.06)$ \\
\hline Th2 & $3.25(1.97-4.83)$ & $3.67(2.36-5.25)$ & $2.90(1.93-4.06)$ & $3.27(1.88-5.02)$ \\
\hline Th17 & $3.58(2.41$ - 4.97) & $5.21(3.08-7.87)^{* * *}$ & $3.91(2.64-5.42)$ & $5.03(3.05-7.46)^{* * *}$ \\
\hline Treg & $3.72(2.31-5.44)$ & $3.14(1.90-4.67)$ & $3.94(2.40-7.555)$ & $3.04(1.73-6.87)$ \\
\hline Tc17 & $3.95(2.84-5.22)$ & $5.02(2.74-7.94)^{*}$ & $3.79(1.83-6.18)$ & $4.97(3.08-7.30)^{* *}$ \\
\hline Th17/Treg & $1.11(0.54-1.68)$ & $2.02(0.68-3.38)^{* * *}$ & $1.12(0.53-1.72)$ & $2.10(0.41-3.81)^{* *}$ \\
\hline Th17/Th2 & $1.36(0.38-2.35)$ & $1.76(0.40-3.13)$ & $1.49(0.82-2.16)$ & $1.89(0.50-3.25)^{*}$ \\
\hline Tc17/Treg & $1.07(0.79-1.36)$ & $1.34(0.85-1.84)^{* *}$ & $3.04(1.66-4.44)$ & $5.32(1.53-9.11)^{* *}$ \\
\hline IL-6 & $16.59(6.87-40.05)$ & $26.66(11.62-61.18)^{*}$ & $14.16(6.09-32.94)$ & $18.19(6.61-50.06)$ \\
\hline
\end{tabular}

Values are represented as percentage or as Mean (SD-standard deviation) for age, BMI and WHR and as Mean (95\% CI) for variables which were log transformed for analysis. Lipid levels are expressed in mMol/L. Multivariate analysis was used to compare the cellular markers using age and gender, hypertension, diabetes, hyperglycaemia and smoking as covariates. Cytokine levels in serum were measured using Milliplex-Cytomax kit. BMI: Body mass index, DBP: Diastolic blood pressure, LDL: Low density lipoprotein, HDL: High density lipoprotein IL: Interleukin, IFN: Interferon, SBP: Systolic blood pressure, TC: Total cholesterol, TG: Triglycerides, WHR: Waist hip ratio. ${ }^{*} \mathrm{P}<0.05,{ }^{* *} \mathrm{P}<0.005,{ }^{* * *} \mathrm{P}<0.0005$. 
Table 5. Association of classical risk factors and T cell markers with STEMI in young and older patients.

\begin{tabular}{ccc}
\hline Marker & \multicolumn{2}{c}{ Age $>\mathbf{4 5}$ years OR (95\% CI), P Value } \\
\hline & Model $\mathbf{1}$ & Model $\mathbf{2}$ \\
\hline Diabetes & $0.89(0.13-5.8)$, NS & $5.43(1.13-26.03), \mathbf{0 3 4}$ \\
Hyperglycemia & $5.87(1.47-23.47), \mathbf{0 . 0 1 2}$ & $1.99(0.59-6.70)$, NS \\
Hypertension & $2.07(0.29-15.06)$, NS & $11.47(1.80-73.15) \mathbf{0 . 0 1 0}$ \\
Smoking & $2.00(0.28-15.06)$, NS & $2.63(0.84-8.24)$, NS \\
Th17 & $1.38(1.03-1.84), \mathbf{0 . 0 3 2}$ & $1.44(1.11-1.89), \mathbf{0 . 0 0 7}$ \\
Tc17 & $1.20(0.95-1.55)$, NS & $1.32(1.05-1.66), \mathbf{0 . 0 1 8}$ \\
Th17/Treg & $2.65(1.23-5.73), \mathbf{0 . 0 1 3}$ & $3.03(1.38-6.60), \mathbf{0 . 0 0 5}$ \\
Tc17/Treg & $4.76(1.05-21.27), \mathbf{0 . 0 4 3}$ & $1.59(1.14-2.22), \mathbf{0 . 0 0 7}$ \\
\hline
\end{tabular}

Logistic regression analysis was carried out by taking the markers as continuous variable. Classical risk factors, (Age, gender, body mass index, waist hip ratio, hypertension, diabetes, hyperglycaemia, LDL and current smoking) were taken as covariates.

IL-22 and IL-23 which in turn can induce the expression of an array of pro inflammatory cytokines and chemokines (TNF- $\alpha$, IL-1, IL-6 CXCL1, CXCL2, and CCL7) to intensify inflammation [36]. IL-17 has been implicated in several autoimmune diseases and was found to induce apoptosis of smooth muscle cells and endothelial cells which could lead to plaque rupture [37]. Th17 can aggravate the development of atherosclerosis and was recently shown to be involved in the disruption of vulnerable plaque in mice model, suggesting their role in triggering and acute event [38] [39].

Although it is known that CD8 cells may also contribute to the pathogenesis of acute MI, changes in circulating CD8 cells have not been explored in detail [40]. IL-17-producing $\mathrm{CD}^{+} \mathrm{T}$ cell subpopulation, termed as Tc17 with distinct role in the pathogenesis of autoimmune diseases including multiple sclerosis, psoriasis and autoimmune encephalomyelitis was recently described in human and mice [41]-[43]. In another study T cells infiltrating the coronary artery were found to produce IL-17 concomitantly with IFN- $\gamma$ and induce pro-inflammatory responses in vascular smooth muscle cells [16]. We observed a significant increase in the CD4 and CD8 cells secreting IL-17 and CD4 cells double positive for IL-17and IFN $\gamma$ in MI patients. Plasma levels of IL-17 and IL-6 were higher in patients, suggesting that IL-17 mediated inflammation plays a pivotal role in the acute coronary disease in the Indian population. IL-6 has been reported to be higher in AMI patients and identified earlier as an independent risk factor [44], which is supported by our study.

Regulatory T cells (Tregs) limit inflammation and exert an immune regulatory function and are known to have an anti atherogenic effect [45]. Adoptive transfer of Treg cells can reduce the plaque development [46] and depletion of Tregs enhances atherosclerosis in mice models, suggesting a protective role for these cells. Patients with unstable angina were reported to have lower Tregs [18]. Dysfunction of Treg cells was also reported in experimental animal models of atherosclerosis [47]. Regulatory $\mathrm{T}$ cells are known to suppress the recruitment of macrophages and foam cell formation in the lesion, increase phagocytosis, and collagen biosynthesis, thus resolving inflammation [48] [49]. Thus it is conceivable that loss of Treg cells with a concomitant increase in Th17 cells result in acute inflammation which is a prerequisite for plaque instability and rupture. Our data supports the study by Cheng et al. who also reported a significant increase in peripheral Th17 number and Th17/ Treg functional imbalance in patients with AMI, suggesting a possible role for these cells in plaque destabilization and the onset of acute disease [15]. Our results for the first time suggest the importance of Tc17 cells and their imbalance with Treg cells in atherothrombosis. The ratio of Th17 to Treg and Tc17 to Treg showed 2.9 and 2.2 times higher risk association with acute MI in Indians. Addition of this ratio to classical risk factors could significantly increase the sensitivity and specificity discrimination of patients from control. Our results also indicate that elevated frequencies of circulating Treg cells in peripheral blood are associated with 17\% lower risk of developing MI. Peripheral T cells from MI patients showed increased reactivity to Ox-LDL and HSP60 with significantly higher proliferative response. These proliferating $\mathrm{T}$ cells were found to have higher intracellular expression of IL-17, suggesting that the increased pool of Th17/Tc17 cells in circulation could be caused by auto reactivity to HSP60 and Ox-LDL. Stress probably plays an important in the atherothrombotic disease in the Indian population. 
Th1 cells $\left(\mathrm{CD} 4^{+} \mathrm{IFN}-\gamma^{+}\right)$are known to play a major role in T cell-mediated injury in coronary atherosclerosis [50]. Patients with unstable angina (UA) were reported to have an increased frequency of $\mathrm{CD}^{+} \mathrm{T}_{\text {lymphocytes }}$ lacking the co-stimulatory molecule CD28 $\left(\mathrm{CD}^{+} \mathrm{CD} 28^{\text {null }}\right)$, which secrete high level IFN $\gamma$ and perforin [22] [23]. It was also suggested that $\mathrm{CD} 4^{+} \mathrm{CD} 28^{\text {null }}$ can constitute up to $50 \%$ of the total $\mathrm{CD} 4^{+}$compartment and are a dominant population of IFN $\gamma$ producing cells in patients with Unstable Angina [22] [23]. Several recent studies have reported that expansion of $\mathrm{CD} 4^{+} \mathrm{CD} 28^{\text {null }}$ cells can mediate plaque instability and recurrence of AMI [33] [51]. Surprisingly we did not observe any difference in the $\mathrm{CD} 4^{+} \mathrm{CD} 28^{\text {null }}$ cells or Th1 cells in our population. These results suggest the possibility of existence of a different mechanism of atherothrombotic disease in the Indian patients.

India is an epicenter for coronary artery disease accounting for $25 \%$ of all mortality [52]. Indians get affected with more severe form of coronary heart disease at a much younger age [24] [53] [54], which cannot explained by conventional risk factors alone [55]. Susceptibility to acute myocardial infarction is more prevalent in South Asian migrants in different countries despite low levels of traditional risk factors, suggesting an inherent difference in the presentation of disease in this population [56].

Young patients ( $<45$ years) with MI, without conventional risk factors showed an increase in circulating Th17 cells and an imbalance in the ratio of Th17 and Tc17 to Tregs compared to control. Th17/Treg ratio emerged as a significant risk association marker in the young patients. In older patients ( $>45$ years), Diabetes and Hypertension emerged as significant risk factors apart from Th17, Tc17 and Th17/Treg ratio. Hyperglycemia was found to be highly prevalent in young patients, and was associated with considerable risk of MI. It is interesting to note that most of these hyperglycemic individuals were not diabetic. Association between Stress hyperglycemia and poor cardiac outcome has been reported in Mi patients [57]. High blood sugar levels are known to have proinflammatory action and can increase circulating concentrations of IL-6, IL-18 and TNF- $\alpha$ [58]. IL-6 is a pleiotropic cytokine and can influence the T cell development. Naïve cells are known to differentiate into Th17 cells in the presence of IL-6 and TGF- $\beta$ [59]. It is likely that untreated hyperglycemia in young adults' influences the differentiation of Th17 cells which in turn augments inflammation and pathogenesis associated with acute coronary syndrome

Few limitations of the study need to be considered. This being a case control study, retrospective in nature, samples were collected after the event, which limits the causal relationship between the elevation in Th17 cells and occurrence of an AMI event. Although Th17 has been shown to exacerbate atherosclerosis and induce plaque disruption in mice model, causal role of these cells have not been studied in CAD patients. We propose to collect samples post MI from the same subjects and analyse the same markers to understand if the elevation of Th17 causes MI or it is a consequence of an acute event.

\section{Conclusion}

In conclusion, our results suggest an important role for Th17 and Tc17 cells in acute coronary disease in Indian population. HSP60 and Ox-LDL may contribute to this response and pathogenesis of AMI in Indian population. Young MI patients with no apparent risk factors could be distinguished by the increase in Th17 cells and Th17/Treg ratio in peripheral blood. The ratio of Th17 to Treg cells in the peripheral blood emerged as an independent marker showing significant association with acute myocardial infarction and could be developed as a potential new marker to differentiate individuals at a higher risk for developing an acute clinical event.

\section{Acknowledgements}

We gratefully acknowledge the support of the trustees of Thrombosis Research Institute, London and Bangalore and the Tata Social Welfare Trust, India (TSWT/IG/SNB/JP/Sdm). Support for the PhD program by Bharti Foundation is gratefully acknowledged.

\section{Funding}

The study was supported by the Indian Council for Medical Sciences (ICMR), Government of India (5/4/14/11-NCD-II).

\section{References}

[1] World Health Organization (2014) World Health Statistics 2014. World Health Organization, Geneva. 
http://www.who.int/gho/publications/world_health_statistics/2014/en

[2] Sherer, Y. and Shoenfeld, Y. (2006) Mechanisms of Disease: Atherosclerosis in Autoimmune Diseases. Nature Clinical Practice Rheumatology, 2, 99-106. http://dx.doi.org/10.1038/ncprheum0092

[3] Robertson, A.K. and Hansson, G.K. (2006) T Cells in Atherogenesis: For Better or for Worse? Arteriosclerosis, Thrombosis, and Vascular Biology, 26, 2421-2432. http://dx.doi.org/10.1161/01.ATV.0000245830.29764.84

[4] Khallou-Laschet, J., Caligiuri, G., Groyer, E., Tupin, E., Gaston, A.T., Poirier, B., Kronenberg, M., Cohen, J.L., Klatzmann, D., Kaveri, S.V. and Nicoletti, A. (2006) The Proatherogenic Role of T Cells Requires Cell Division and Is Dependent on the Stage of the Disease. Arteriosclerosis, Thrombosis, and Vascular Biology, 26, 353-358.

[5] George, J. (2008) Mechanisms of Disease: The Evolving Role of Regulatory T Cells in Atherosclerosis. Nature Clinical Practice Cardiovascular Medicine Nature Clinical Practice Cardiovascular Medicine, 5, 531-540. http://dx.doi.org/10.1038/ncpcardio1279

[6] Hansson, G.K. and Berne, G.P. (2004) Atherosclerosis and the Immune System. Acta Paediatrica, 93, 63-69. http://dx.doi.org/10.1111/j.1651-2227.2004.tb00241.x

[7] Hansson, G.K. and Libby, P. (2006) The Immune Response in Atherosclerosis: A Double-Edged Sword. Nature Reviews Immunology, 6, 508-519. http://dx.doi.org/10.1038/nri1882

[8] Taleb, S., Tedgui, A. and Mallat, Z. (2008) Regulatory T-Cell Immunity and Its Relevance to Atherosclerosis. Journal of Internal Medicine, 263, 489-499. http://dx.doi.org/10.1111/j.1365-2796.2008.01944.X

[9] Fontenot, J.D., Gavin, M.A. and Rudensky, A.Y. (2003) Foxp3 Programs the Development and Function of CD4+CD25+ Regulatory T Cells. Nature Immunology, 4, 330-336. http://dx.doi.org/10.1038/ni904

[10] Dejaco, C., Duftner, C., Grubeck-Loebenstein, B. and Schirmer, M. (2006) Imbalance of Regulatory T Cells in Human Autoimmune Diseases. Immunology, 117, 289-300. http://dx.doi.org/10.1111/j.1365-2567.2005.02317.x

[11] Tesmer, L.A., Lundy, S.K., Sarkar, S. and Fox, D.A. (2008) Th17 Cells in Human Disease. Immunological Reviews, 223, 87-113. http://dx.doi.org/10.1111/j.1600-065X.2008.00628.x

[12] Bettelli, E., Carrier, Y., Gao, W., Korn, T., Strom, T.B., Oukka, M., Weiner, H.L. and Kuchroo, V.K. (2006) Reciprocal Developmental Pathways for the Generation of Pathogenic Effector $\mathrm{T}_{\mathrm{H}} 17$ and Regulatory $\mathrm{T}$ Cells. Nature, 441, 235-238. http://dx.doi.org/10.1038/nature04753

[13] Eisenstein, E.M. and Williams, C.B. (2009) The $\mathrm{T}_{\text {reg }} /$ Th17 Cell Balance: A New Paradigm for Autoimmunity. Pediatric Research, 65, 26R-31R. http://dx.doi.org/10.1203/PDR.0b013e31819e76c7

[14] Noack, M. and Miossec, P. (2014) Th17 and Regulatory T Cell Balance in Autoimmune and Inflammatory Diseases. Autoimmunity Reviews, 13, 668-677. http://dx.doi.org/10.1016/j.autrev.2013.12.004

[15] Cheng, X., Yu, X., Ding, Y.J., Fu, Q.Q., Xie, J.J., Tang, T.T., Yao, R., Chen, Y. and Liao, Y.H. (2008) The Th17/Treg Imbalance in Patients with Acute Coronary Syndrome. Clinical Immunology, 127, 89-97. http://dx.doi.org/10.1016/j.clim.2008.01.009

[16] Eid, R.E., Rao, D.A., Zhou, J., Lo, S.F., Ranjbaran, H., Gallo, A., Sokol, S.I., Pfau, S., Pober, J.S. and Tellides, G. (2009) Interleukin-17 and Interferon-Gamma Are Produced Concomitantly by Human Coronary Artery-Infiltrating $T$ Cells and Act Synergistically on Vascular Smooth Muscle Cells. Circulation, 119, 1424-1432. http://dx.doi.org/10.1161/CIRCULATIONAHA.108.827618

[17] Han, S.F., Liu, P., Zhang, W., Bu, L., Shen, M., Li, H., Fan, Y.H., Cheng, K., Cheng, H.X., Li, C.X. and Jia, G.L. (2007) The Opposite-Direction Modulation of CD4+CD25+ Tregs and T Helper 1 Cells in Acute Coronary Syndromes. Clinical Immunology, 124, 90-97. http://dx.doi.org/10.1016/j.clim.2007.03.546

[18] Mor, A., Luboshits, G., Planer, D., Keren, G. and George, J. (2006) Altered Status of CD4 ${ }^{+}$CD25 ${ }^{+}$Regulatory T Cells in Patients with Acute Coronary Syndromes. European Heart Journal, 27, 2530-2537. http://dx.doi.org/10.1093/eurheartj/ehl222

[19] Wang, Z., Lee, J., Zhang, Y., Wang, H., Liu, X., Shang, F. and Zheng, Q. (2011) Increased Th17 Cells in Coronary Artery Disease Are Associated with Neutrophilic Inflammation. Scandinavian Cardiovascular Journal, 45, 54-61. http://dx.doi.org/10.3109/14017431.2010.491123

[20] Zhao, Z., Wu, Y., Cheng, M., Ji, Y., Yang, X., Liu, P., Jia, S. and Yuan, Z. (2011) Activation of Th17/Th1 and Th1, but Not Th17, Is Associated with the Acute Cardiac Event in Patients with Acute Coronary Syndrome. Atherosclerosis, 217, 518-524. http://dx.doi.org/10.1016/j.atherosclerosis.2011.03.043

[21] del Rosario Espinoza Mora, M., Bohm, M. and Link, A. (2014) The Th17/Treg Imbalance in Patients with Cardiogenic Shock. Clinical Research in Cardiology, 103, 301-313. http://dx.doi.org/10.1007/s00392-013-0656-0

[22] Zal, B., Kaski, J.C., Arno, G., Akiyu, J.P., Xu, Q., Cole, D., Whelan, M., Russell, N., Madrigal, J.A., Dodi, I.A. and Baboonian, C. (2004) Heat-Shock Protein 60-Reactive CD4 ${ }^{+}$CD28 ${ }^{\text {null }}$ T Cells in Patients with Acute Coronary Syndromes. Circulation, 109, 1230-1235. http://dx.doi.org/10.1161/01.CIR.0000118476.29352.2A 
[23] Liuzzo, G., Goronzy, J.J., Yang, H., Kopecky, S.L., Holmes, D.R., Frye, R.L. and Weyand, C.M. (2000) Monoclonal T-Cell Proliferation and Plaque Instability in Acute Coronary Syndromes. Circulation, 101, 2883-2888. http://dx.doi.org/10.1161/01.CIR.101.25.2883

[24] Gupta, M. and Brister, S. (2006) Is South Asian Ethnicity an Independent Cardiovascular Risk Factor? Canadian Journal of Cardiology, 22, 193-197. http://dx.doi.org/10.1016/S0828-282X(06)70895-9

[25] Gupta, R., Joshi, P., Mohan, V., Reddy, K.S. and Yusuf, S. (2008) Epidemiology and Causation of Coronary Heart Disease and Stroke in India. Heart, 94, 16-26. http://dx.doi.org/10.1136/hrt.2007.132951

[26] Hawkins, E.D., Hommel, M., Turner, M.L., Battye, F.L., Markham, J.F. and Hodgkin, P.D. (2007) Measuring Lymphocyte Proliferation, Survival and Differentiation Using CFSE Time-Series Data. Nature Protocols, 2, 2057-2067. http://dx.doi.org/10.1038/nprot.2007.297

[27] Quah, B.J., Warren, H.S. and Parish, C.R. (2007) Monitoring Lymphocyte Proliferation in Vitro and in Vivo with the Intracellular Fluorescent Dye Carboxyfluorescein Diacetate Succinimidyl Ester. Nature Protocols, 2, 2049-2056. http://dx.doi.org/10.1038/nprot.2007.296

[28] Lopes-Virella, M.F., Koskinen, S., Mironova, M., Horne, D., Klein, R., Chassereau, C., Enockson, C. and Virella, G. (2000) The Preparation of Copper-Oxidized LDL for the Measurement of Oxidized LDL Antibodies by EIA. Atherosclerosis, 152, 107-115. http://dx.doi.org/10.1016/S0021-9150(99)00456-6

[29] Tesfa, L., Volk, H.D. and Kern, F. (2003) A Protocol for Combining Proliferation, Tetramer Staining and Intracellular Cytokine Detection for the Flow-Cytometric Analysis of Antigen Specific T-Cells. Journal of Biological Regulators \& Homeostatic Agents, 17, 366-370.

[30] Schmidt, T. and Sester, M. (2013) Detection of Antigen-Specific T Cells Based on Intracellular Cytokine Staining Using Flow-Cytometry. Methods in Molecular Biology, 1064, 267-274. http://dx.doi.org/10.1007/978-1-62703-601-6_19

[31] Fink, E.L. (2009) The FAQs on Data Transformation. Communication Monographs, 76, 379-397. http://dx.doi.org/10.1080/03637750903310352

[32] Swirski, F.K. and Nahrendorf, M. (2013) Leukocyte Behavior in Atherosclerosis, Myocardial Infarction, and Heart Failure. Science, 339, 161-166. http://dx.doi.org/10.1126/science.1230719

[33] Liuzzo, G., Biasucci, L.M., Trotta, G., Brugaletta, S., Pinnelli, M., Digianuario, G., Rizzello, V., Rebuzzi, A.G., Rumi, C., Maseri, A. and Crea, F. (2007) Unusual CD4 ${ }^{+}$CD28 ${ }^{\text {null }}$ T Lymphocytes and Recurrence of Acute Coronary Events. Journal of the American College of Cardiology, 50, 1450-1458. http://dx.doi.org/10.1016/j.jacc.2007.06.040

[34] Liuzzo, G., Kopecky, S.L., Frye, R.L., O’Fallon, W.M., Maseri, A., Goronzy, J.J. and Weyand, C.M. (1999) Perturbation of the T-Cell Repertoire in Patients with Unstable Angina. Circulation, 100, 2135-2139. http://dx.doi.org/10.1161/01.CIR.100.21.2135

[35] Hansson, G.K. (2005) Inflammation, Atherosclerosis, and Coronary Artery Disease. The New England Journal of Medicine, 352, 1685-1695. http://dx.doi.org/10.1056/NEJMra043430

[36] Park, H., Li, Z., Yang, X.O., Chang, S.H., Nurieva, R., Wang, Y.H., Wang, Y., Hood, L., Zhu, Z., Tian, Q. and Dong, C. (2005) A Distinct Lineage of CD4 T Cells Regulates Tissue Inflammation by Producing Interleukin 17. Nature Immunology, 6, 1133-1141. http://dx.doi.org/10.1038/ni1261

[37] Ma, T., Gao, Q., Zhu, F., Guo, C., Wang, Q., Gao, F. and Zhang, L. (2013) Th17 Cells and IL-17 Are Involved in the Disruption of Vulnerable Plaques Triggered by Short-Term Combination Stimulation in Apolipoprotein E-Knockout Mice. Cellular \& Molecular Immunology, 10, 338-348. http://dx.doi.org/10.1038/cmi.2013.4

[38] Gao, Q., Jiang, Y., Ma, T., Zhu, F., Gao, F., Zhang, P., Guo, C., Wang, Q., Wang, X., Ma, C., Zhang, Y., Chen, W. and Zhang, L. (2010) A Critical Function of Th17 Proinflammatory Cells in the Development of Atherosclerotic Plaque in Mice. The Journal of Immunology, 185, 5820-5827. http://dx.doi.org/10.4049/jimmunol.1000116

[39] Ma, T., Gao, Q., Zhu, F., Guo, C., Wang, Q., Gao, F. and Zhang, L. (2013) Th17 Cells and IL-17 Are Involved in the Disruption of Vulnerable Plaques Triggered by Short-Term Combination Stimulation in Apolipoprotein E-Knockout Mice. Cellular \& Molecular Immunology, 10, 338-348. http://dx.doi.org/10.1038/cmi.2013.4

[40] Tae Yu, H., Youn, J.-C., Lee, J., Park, S., Chi, H.-S., Lee, J., Choi, C., Park, S., Choi, D., Ha, J.-W. and Shin, E.-C. (2014) Characterization of $\mathrm{CD}^{+} \mathrm{CD}^{+} 7^{+} \mathrm{T}$ Cells in Patients with Acute Myocardial Infarction. Cellular \& Molecular Immunology, 12, 466-473.

[41] Intlekofer, A.M., Banerjee, A., Takemoto, N., Gordon, S.M., Dejong, C.S., Shin, H., Hunter, C.A., Wherry, E.J., Lindsten, T. and Reiner, S.L. (2008) Anomalous Type 17 Response to Viral Infection by CD8 ${ }^{+}$T Cells Lacking T-Bet and Eomesodermin. Science, 321, 408-411. http://dx.doi.org/10.1126/science.1159806

[42] Tzartos, J.S., Friese, M.A., Craner, M.J., Palace, J., Newcombe, J., Esiri, M.M. and Fugger, L. (2008) Interleukin-17 Production in Central Nervous System-Infiltrating T Cells and Glial Cells Is Associated with Active Disease in Multiple Sclerosis. American Journal of Pathology, 172, 146-155. http://dx.doi.org/10.2353/ajpath.2008.070690 
[43] Ortega, C., Fernandez, A.S., Carrillo, J.M., Romero, P., Molina, I.J., Moreno, J.C. and Santamaria, M. (2009) IL-17-Producing $\mathrm{CD}^{+} \mathrm{T}$ Lymphocytes from Psoriasis Skin Plaques Are Cytotoxic Effector Cells That Secrete Th17-Related Cytokines. Journal of Leukocyte Biology, 86, 435-443. http://dx.doi.org/10.1189/JLB.0109046

[44] Ridker, P.M., Rifai, N., Stampfer, M.J. and Hennekens, C.H. (2000) Plasma Concentration of Interleukin-6 and the Risk of Future Myocardial Infarction among Apparently Healthy Men. Circulation, 101, 1767-1772. http://dx.doi.org/10.1161/01.CIR.101.15.1767

[45] Jager, A. and Kuchroo, V.K. (2010) Effector and Regulatory T-Cell Subsets in Autoimmunity and Tissue Inflammation. Scandinavian Journal of Immunology, 72, 173-184. http://dx.doi.org/10.1111/j.1365-3083.2010.02432.X

[46] Mor, A., Planer, D., Luboshits, G., Afek, A., Metzger, S., Chajek-Shaul, T., Keren, G. and George, J. (2007) Role of Naturally Occurring $\mathrm{CD}^{+} \mathrm{CD} 25^{+}$Regulatory T Cells in Experimental Atherosclerosis. Arteriosclerosis, Thrombosis, and Vascular Biology, 27, 893-900. http://dx.doi.org/10.1161/01.ATV.0000259365.31469.89

[47] Gotsman, I., Grabie, N., Gupta, R., Dacosta, R., MacConmara, M., Lederer, J., Sukhova, G., Witztum, J.L., Sharpe, A.H. and Lichtman, A.H. (2006) Impaired Regulatory T-Cell Response and Enhanced Atherosclerosis in the Absence of Inducible Costimulatory Molecule. Circulation, 114, 2047-2055. http://dx.doi.org/10.1161/CIRCULATIONAHA.106.633263

[48] Lutgens, E., Gijbels, M., Smook, M., Heeringa, P., Gotwals, P., Koteliansky, V.E. and Daemen, M.J. (2002) Transforming Growth Factor-Beta Mediates Balance between Inflammation and Fibrosis during Plaque Progression. Arteriosclerosis, Thrombosis, and Vascular Biology, 22, 975-982. http://dx.doi.org/10.1161/01.ATV.0000019729.39500.2F

[49] Mallat, Z., Gojova, A., Marchiol-Fournigault, C., Esposito, B., Kamate, C., Merval, R., Fradelizi, D. and Tedgui, A. (2001) Inhibition of Transforming Growth Factor-Beta Signaling Accelerates Atherosclerosis and Induces an Unstable Plaque Phenotype in Mice. Circulation Research, 89, 930-934. http://dx.doi.org/10.1161/hh2201.099415

[50] Wang, Y., Burns, W.R., Tang, P.C., Yi, T., Schechner, J.S., Zerwes, H.G., Sessa, W.C., Lorber, M.I., Pober, J.S. and Tellides, G. (2004) Interferon-Gamma Plays a Nonredundant Role in Mediating T Cell-Dependent Outward Vascular Remodeling of Allogeneic Human Coronary Arteries. The FASEB Journal, 18, 606-608.

[51] Dumitriu, I.E., Araguas, E.T., Baboonian, C. and Kaski, J.C. (2009) CD4 ${ }^{+}$CD28 $8^{\text {null }}$ T Cells in Coronary Artery Disease: When Helpers Become Killers. Cardiovascular Research, 81, 11-19. http://dx.doi.org/10.1093/cvr/cvn248

[52] Gupta, R. (2005) Burden of Coronary Heart Disease in India. Indian Heart Journal, 57, 632-638.

[53] Gupta, M., Singh, N. and Verma, S. (2006) South Asians and Cardiovascular Risk: What Clinicians Should Know. Circulation, 113, e924-e929. http://dx.doi.org/10.1161/circulationaha.105.583815

[54] Sharma, M. and Ganguly, N.K. (2005) Premature Coronary Artery Disease in Indians and Its Associated Risk Factors. Vascular Health and Risk Management, 1, 217-225.

[55] Sekhri, T., Kanwar, R.S., Wilfred, R., Chugh, P., Chhillar, M., Aggarwal, R., Sharma, Y.K., Sethi, J., Sundriyal, J., Bhadra, K., Singh, S., Rautela, N., Chand, T., Singh, M. and Singh, S.K. (2014) Prevalence of Risk Factors for Coronary Artery Disease in an Urban Indian Population. BMJ Open, 4, e005346. http://dx.doi.org/10.1136/bmjopen-2014-005346

[56] Joshi, P., Islam, S., Pais, P., Reddy, S., Dorairaj, P., Kazmi, K., Pandey, M.R., Haque, S., Mendis, S., Rangarajan, S. and Yusuf, S. (2007) Risk Factors for Early Myocardial Infarction in South Asians Compared with Individuals in Other Countries. JAMA, 297, 286-294. http://dx.doi.org/10.1001/jama.297.3.286

[57] Capes, S.E., Hunt, D., Malmberg, K. and Gerstein, H.C. (2000) Stress Hyperglycaemia and Increased Risk of Death after Myocardial Infarction in Patients with and without Diabetes: A Systematic Overview. Lancet, 355, 773-778. http://dx.doi.org/10.1016/S0140-6736(99)08415-9

[58] Dandona, P., Aljada, A. and Bandyopadhyay, A. (2003) The Potential Therapeutic Role of Insulin in Acute Myocardial Infarction in Patients Admitted to Intensive Care and in Those with Unspecified Hyperglycemia. Diabetes Care, 26, 516-519. http://dx.doi.org/10.2337/diacare.26.2.516

[59] Mangan, P.R., Harrington, L.E., O’Quinn, D.B., Helms, W.S., Bullard, D.C., Elson, C.O., Hatton, R.D., Wahl, S.M., Schoeb, T.R. and Weaver, C.T. (2006) Transforming Growth Factor-Beta Induces Development of the $\mathrm{T}_{\mathrm{H}} 17$ Lineage. Nature, 441, 231-234. http://dx.doi.org/10.1038/nature04754 